\title{
Long term betaine supplementation regulates genes involved in lipid and cholesterol metabolism of two muscles from an obese pig breed
}

\author{
A. Albuquerque ${ }^{a}$, José A. Neves ${ }^{b}$, M. Redondeiro ${ }^{a}$, M. Laranjo ${ }^{a}$, M.R. Félix ${ }^{c}$, Amadeu Freitas $^{b}$, \\ José L. Tirapicos ${ }^{\mathrm{d}}$, José M. Martins ${ }^{\mathrm{b}, *}$ \\ a ICAAM-Instituto de Ciências Agrárias e Ambientais Mediterrânicas, Universidade de Évora, Núcleo da Mitra, Ap. 94, 7006-554 Évora, Portugal \\ b ICAAM, Departamento de Zootecnia, Universidade de Évora, Pólo da Mitra, Ap. 94, 7002-554 Évora, Portugal \\ ' ICAAM, Departamento de Fitotecnia, Universidade de Évora, 7002-554 Évora, Portugal \\ d ICAAM, Departamento de Medicina Veterinária, Universidade de Évora, 7002-554 Évora, Portugal
}

\section{A R T I C L E I N F O}

\section{Article history:}

Received 7 March 2016

Received in revised form 20 October 2016

Accepted 24 October 2016

Available online 27 October 2016

\section{Keywords:}

Betaine

Longissimus lumborum

Biceps femoris

Intramuscular fat and cholesterol content

Gene expression

Alentejano pig

\begin{abstract}
A B S T R A C T
This study evaluates the effects of betaine supplementation $\left(1 \mathrm{~g} \mathrm{~kg}^{-1}\right.$ for 20 weeks) on the regulation of genes involved in lipid and cholesterol metabolism of Longissimus lumborum and Biceps femoris from obese Alentejano pigs. Betaine supplementation led to an increase in total cholesterol in both muscles, complementing results previously published indicating a significant increase on the intramuscular lipid content. The expression of twelve genes involved in lipogenesis, lipolysis/FA oxidation, FA transport, and cholesterol metabolism, as well as two transcription factors were also evaluated. Genes related to lipid and cholesterol synthesis plus FA transport were consistently up-regulated in both muscles of betaine fed pigs. On the other hand, genes related to lipolysis/FA oxidation were not affected or down-regulated by betaine supplementation.

Our data suggest that the underlying mechanism regulating IMF and cholesterol accumulation in Alentejano pigs supplemented with betaine is associated with the up-regulation of genes involved in lipid synthesis, FA transport, and cholesterol synthesis.
\end{abstract}

(c) 2016 Elsevier Ltd. All rights reserved.

\section{Introduction}

Betaine, i.e., $N, N, N$-trimethylglycine, is used by mammals primarily as an osmolyte (Lang, 2007), and as a methyl donor for the remethylation of homocysteine to methionine (Schwab et al., 2006). This nontoxic and chemically stable product has been used as a dietary supplement in pig nutrition to reduce fat deposition and increase lean muscle mass with inconsistent results so far. In lean pigs, betaine supplementation reduces (Cadogan, Campbell, Harrison, \& Edwards, 1993), increases (Haydon, Campbell, \& Prince, 1995) or has no effect on body fat (Matthews, Southern, Pontif, Higbie, \& Bidner, 1998; Overland, Rorvik, \& Skrede, 1999). On the other hand, methionine

Abbreviations: ACC, Acetyl-CoA carboxylase; ADPN, adiponectin; AL, Alentejano; BW, body weight; $C$, commercial; $C B, C$ diet supplemented with betaine; FA, fatty acid; FASN, Fatty acid synthase; H-FABP, Heart-type fatty acid binding protein; HMGCR, 3-Hydroxy-3methyl-glutaryl-CoA reductase; HPRT1, hypoxanthine phosphoribosyltransferase 1; HSL, Hormone-sensitive lipase; IMF, intramuscular fat; LDLr, Low-Density Lipoprotein Receptor; LPL, Lipoprotein lipase; MCPT1, Muscle-type carnitine palmitoyltransferase 1; MUFA, monounsaturated fatty acid; PPAR $\alpha$, Peroxisome proliferator-activated receptor alpha; PPAR $\gamma$, Peroxisome proliferator-activated receptor gamma; PUFA, polyunsaturated fatty acid; SCD, Stearoyl-CoA desaturase; SFA, saturated fatty acid; TAG, triacylglycerol.

* Corresponding author.

E-mail address: jmartins@uevora.pt (J.M. Martins). obtained through betaine remethylation of homocysteine can be converted to S-adenosylmethionine. This compound is further converted to S-adenosylhomocysteine by glycine $\mathrm{N}$-methyltransferase, thereby donating the methyl group for DNA and protein methylation (Bestor, 2000; Cai et al., 2014). Consequently, betaine may modulate gene expression through modifying epigenetic marks such as DNA and histone methylation (Bestor, 2000).

Following years of intensive selection for leaner pigs, resulting in a reduction in meat eating quality, in the last decade the market has shifted to an increasing demand for better quality pork (Cánovas et al., 2010; Gao et al., 2010). In fact, although suspicious of the subcutaneous or abdominal fat depots, European consumers prefer meat with a minimal amount of intramuscular fat (IMF) which is known to contribute to eating quality of pork (Doran et al., 2006; Wood et al., 2008). Meanwhile, the contribution of several lipogenic enzymes to the tissue-specific regulation of fat deposition in pigs remains unclear, as well as the mechanisms regulating IMF and subcutaneous fat deposition ( $\mathrm{Li}$, Li, et al., 2011; Shan, Wu, Reng, \& Wang, 2009). Knowledge of these mechanisms could contribute to the identification of physiological candidate genes used for evaluation of effectiveness of genetic selection or dietary manipulations (Cánovas et al., 2010; Gao et al., 2010; Liu et al., 2015).

The Alentejano (AL) pig, reared in the south of Portugal, is characterized by slow growth rates, high lipogenic activity at early stages of development, and a higher monounsaturated fatty acid (MUFA) 